\title{
The selected types of activities and motivators of multichannel purchase among the generation $Y$ consumers
}

\section{Wybrane typy działań i motywów zakupów wielokanałowych wśród konsumentów pokolenia $Y$}

\author{
mgr Liwia Delińska \\ Uniwersytet Gdański, Wydział Zarządzania, Katedra Marketingu \\ ORCID: 0000-0002-1183-6247 \\ e-mail: liwia.delinska@ug.edu.pl \\ dr Sylwia Badowska \\ Uniwersytet Gdański, Wydział Zarządzania, Katedra Marketingu \\ ORCID: 0000-0001-6332-1184 \\ e-mail: sylwia.badowska@ug.edu.pl
}

\begin{abstract}
The purpose of this paper is to investigate whether and how the generation $\mathrm{Y}$ changes shopping channels in their consumption decision path. Linking the online and offline channels in consumer journey has been evaluated. The first part of the work presents literature review - shopping behaviour patterns among generation Y, online and offline channels in the purchasing process, multichannel and omnichannel perspectives. The second part of the work presents the results of authors' original empirical pilot research on the the young consumers' selected multichannel purchase activities and motivations to combine and exchang shopping channels. In this study, the selective quota sampling procedure was used. The study covers 235 students of the Faculty of Management at the University of Gdansk in 2017. The results suggest that multichannel purchase activities undertaken by the $\mathrm{Y}$ generation concerned a product contact, seeing it as well as buying and collecting it. What's more both saving time and money are the prerequisites for online shopping. Online and offline retails have to adapt to new forms of shopping that have become more popular among younger consumers. It is reasonable to conclude that multichannel and omnichannel are a challenge for enterprises targeting their offer to consumers belonging to the $\mathrm{Y}$ generation.
\end{abstract}

Keywords

consumer behaviour, purchase process, multichannel purchase, online purchase, offline purchase

Celem artykułu jest prezentacja wyników badań dotyczących zmiany kanałów zakupowych podczas procesu podejmowania decyzji zakupowych przez przedstawicieli pokolenia Y. Dokonano analizy przemieszczania się konsumentów pomiędzy kanałami online i offline w trakcie ścieżki zakupowej. W pierwszej części pracy przedstawiono przegląd literatury — wzorce zachowań zakupowych wśród generacji Y, kanały podejmowania decyzji zakupowej online i offline oraz perspektywę multichannel i omnichannel. Druga część pracy przedstawia autorskie wyniki badań pilotażowych, które dotyczą wybranych działań z zakupów wielokanałowych przez młodych konsumentów oraz ich motywów do łączenia kanałów zakupowych. Zastosowano celowo-kwotowy dobór próby. Badanie zrealizowano wśród 235 studentów Wydziału Zarząadzania Uniwersytetu Gdańskiego w 2017 r. Wyniki sugerują, że wielokanałowe zakupy realizowane przez pokolenie Y dotyczą kontaktu z produktem, jego obejrzenia, nabycia oraz odbioru. Co więcej, zarówno oszczędność czasu, jak i pieniędzy są czynnikami motywującymi do zakupów internetowych. Zarówno sprzedawcy online, jak i offline muszą dostosować się do 
nowych form zakupów, które stały się popularne wśród młodszych konsumentów. Można stwierdzić, iż multichannel i omnichannel stanowią wyzwanie dla przedsiębiorstw kierujących swoją ofertę do konsumentów z pokolenia Y.

\section{Slowa kluczowe}

zachowanie konsumenta, proces zakupu, multichannel, zakup online, zakup offline

JEL: M31, O33, L63

Str. 31-39

\section{References}

Badrinarayanan, V., Becerra, E. P., Chung-Hyun K., \& Madhavaram, S. (2012). Transference and congruence effects on purchase intentions in online stores of multi-channel retailers: Initial evidence from the U.S. and South Korea. Journal of the Academy of Marketing Science, 40(4), 539-557. https://doi.org/10.1007/s11747-010-0239-9

Cao, L. \& Li, L. (2015). The impact of cross-channel integration on retailers' sales growth. Journal of Retailing, 91(2), 198216. https://doi.org/10.1016/j.jretai.2014.12.005

Chaffey, D. \& Ellis-Chadwick F. (2016). Digital Marketing. Strategy, Implementation and Practice. Prentice Hall International. Comarch \& Kantar TNS. (2017). Przyszłość zakupów. Najważniejsze trendy w retail dziś i w roku 2013. Retrieved from http://www.przyszlosczakupow.comarch.pl

Eurostat. (2017). E-commerce statistics for individuals. Retrieved from http://ec.europa.eu/eurostat/statisticsexplained/index.php?title=Ecommerce_statistics_for_individuals\#General_overview

Gemius/Izba Gospodarki Elektronicznej. (2017). E-Commerce w Polsce. Gemius dla e-Commerce Polska. Retrieved from http://www.gemius.pl/wszystkieartykuly-aktualnosci/najnowsze-dane-o-polskim-e-commerce-juz-dostepne.html

Gupta, A., Chiuan Su B., \& Walter, Z. (2004). An Empirical Study of Consumer Switching from Traditional to Electronic Channel: A purchase decision process perspective. International Journal of Electronic Commerce, 8(3), 131-161. https://doi.org/10.1080/10864415.2004.11044302

GUS. (2017). Spoleczeństwo informacyjne w Polsce. Wyniki badań statystycznych z lat 2013-2017. Warszawa-Szczecin: Urząd Statystyczny w Szczecinie, Ośrodek Statystyki Nauki, Techniki, Innowacji i Społeczeństwa Informacyjnego.

Heitz-Spahn, S. (2013). Cross channel free riding consumer behavior in a multichannel environment: An investigation of shopping motives, sociodemographics and product categories. Journal of Retailing and Consumer Services, 20(6), 570578. https://doi.org/10.1016/j.jretconser.2013.07.006

Herhausen, D., Binder, J., Schoegel, M., \& Herrmann, A. (2015). Integrating bricks with clicks: Retailer-level and channellevel outcomes of online-offline channel integration. Journal of Retailing, 91(2), 309-325. https://doi.org/10.1016/j.jretai.2014.12.009

Howe, N. \& Strauss, W. (2000). Millennials Rising: The Next Great Generation. New York: Vintage Books.

Interaktywnie.com. (2018). Raport Interaktywnie.com: E-commerce 2018. Retrieved from https://interaktywnie.com/ biznes/artykuly/raportyinteraktywnie-com/raport-interaktywnie-com-e-commerce-2018-256819

Izba Gospodarki Elektronicznej. (2018). Omni-commerce. Kupuję wygodnie. Retrieved from http://eizba.pl/files/8415/2641/ 0887/Omnicommerce_Kupuje_wygodnie_2018.pdf

Ishfaq, R., Defee, C. C., Gibson, B. J., \& Raja, U. (2016). Realignment of the physical distribution process in omni-channel fulfillment. International Journal of Physical Distribution and Logistics Management, 46(6/7), 543-561. https://doi.org/10.1108/IJPDLM-02-2015-0032

Kavounis, Y. (2008). The Millennial effect. Brand Strategy, (6). Retrieved from http://www.highbeam.com/doc/1G1186419855.html

Kantar TNS. (2017). E-shopper barometer report 2017. Retrieved from http://www.dpd.com/home/insights/e_ shopper_barometer/e_shopper_barometer_2017

Lazaris C. \& Vrechopoulos A. (2014). From multichannel to "omnichannel" retailing: review of the literature and calls for research. Proceedings from $2^{\text {nd }}$ International Conference on Contemporary Marketing Issues (ICCMI). Athens.

Melero I., Sese F., \& Verhoef P. C. (2016). Recasting the customer experience in today's omni-channel environment. Universia Business Review, 50, 18-37.

Pauwels, K., Leeflang, P., Teerling, M. L., \& Huizingh, E. (2011). Does online information drive offline revenues? Only for specific products and consumer segments! Journal of Retailing, 87(1), 1-17. https://doi.org/10.1016/ j.jretai.2010.10.001 
Pauwels, K. \& Neslin S. A. (2015). Building with bricks and mortar: The revenue impact of opening physical stores in a multichannel environment. Journal of Retailing, 91(2), 182-197. https://doi.org/10.1016/j.jretai.2015.02.001

Prensky, M. (2001). Digital natives, digital immigrants. On the Horizon, 9(5), 1-6.

Refuel Agency. (2015). Millennial teens, digital explorer. Retrieved from http://research.refuelagency.com/wpcontent/uploads/2015/07/Millennial-Teen-Digital-Explorer.pdf

Solomon, M. R. (2016). Consumer Behavior: Buying, Having, and Being. Noida: Pearson India Education Services.

Tapscott, D. (2010). Cyfrowa dorosłość. Jak pokolenie sieci zmienia nasz świat. Warszawa: Wydawnictwa Akademickie i Profesjonalne.

Trenz, M. (2015). Multichannel Commerce A Consumer Perspective on the Integration of Physical and Electronic Channels. Switzerland: Springer.

Wallace, D. W., Giese, J. L., \& Johnson, J. L. (2004). Customer retailer loyalty in the context of multiple channel strategies. Journal of Retailing, 80(4), 249-263. https://doi.org/10.1016/j.jretai.2004.10.002

Van den Bergh, J. \& Behrer, M. (2012). Jak kreować marki, które pokocha pokolenie Y. Warszawa: Edgard.

Verhoef, P. C., Kannan, P. K., \& Inman J. J. (2015). From multi-channel retailing to omni-channel retailing: Introduction to the special issue on multichannel retailing. Journal of Retailing, 91, 174-181. https://doi.org/10.1016/ j.jretai.2015.02.005

Yang, S., Lu, Y., \& Chau, P. (2013). Why do consumers adopt online channel? An empirical investigation of two channel extension mechanisms. Decision Support Systems, 54(2), 858-869. https://doi.org/10.1016/j.dss.2012.09.011

Zhang, J., Farris, P. W., Irvin, J. W., Kushwaha, T., Steenburgh, T. J., \& Weitz, B. A. (2010). Crafting integrated multichannel retailing strategies. Journal of Interactive Marketing, 24(2), 168-180. https://doi.org/10.1016/ j.intmar.2010.02.002 